\title{
Editorial: Contaminated soils and remedial strategies: geotechnical systems between complexity, chaos and sustainability
}

Claudia Vitone MSc, PhD

Associate Professor in Geotechnical Engineering, Department of Civil, Environmental, Land, Building Engineering and Chemistry - DICATECh,

Politecnico di Bari, Bari, Italy

Environmental geotechnics, especially when dealing with contaminated soils and possible remedial strategies as for the articles included here, is facing emblematic cases of different types of complexities in geomechanics. In this respect, the present editorial represents an inspiring opportunity to open geotechnical systems, such as contaminated soils, towards complexity science and adaptive systems (Levy, 1994; Vitone et al., 2018; Waldrop, 1992). This is also in line with the recent addresses by United Nations with respect to risk management: 'The priorities for action spur a new understanding of risk, and the obvious value of discerning the true nature and behaviour of systems rather than a collection of discrete elements. This view allows the use of complexity theory for risk management problems in the context of the [...] 2030 Agenda' (UNDRR, 2019).

As fascinatingly presented by the great physicist Michel Baranger (2002) and illustrated in Figure 1(a) (Ferreira, 2001), complex systems should contain:

(i) many constituents that

(ii) interconnect in intricate ways and

(iii) involve several scales and are capable of

(iv) emerging behaviour.

Moreover, the Cartesian reductionism perspective is part of the complexity theory, since complexity is 'about how a huge number of extremely complicated and dynamic sets of relationships can generate some simple behavioural patterns' (Cilliers, 1998).

However, as shown in Figure 1(b), often environmental systems operate as much as possible at the so-called edge-of-chaos, so that they evolve far from equilibrium and, at some scale, become chaotic: 'chaos destroys the reductionist dream, the dream that we have absolute power if we only know enough about the details' (Baranger, 2002). Chaos theory was pioneered by Lorenz (1972) when studying the dynamics of turbulent flow, and considered that any small change in the initial condition of a complex system may prompt a domino effect, 'Does the flap of a butterfly's wings in Brazil set off a tornado in Texas?'. As a result, for these systems reliable long term predictions are quite difficult, since they depend on the envisaged coupling between the several components and the boundary conditions, which in turn are highly variable across space and with time.
The articles included here cover topics that are mainly addressed towards the predictions of the mechanical response of contaminated/complex soil systems, both in their current condition and after remediation. It follows that they are facing challenging issues since contamination has been proven to push soils towards the edge of chaos, making thus difficult long term behavioural predictions by means of traditional soil mechanics tools (Vitone et al., 2016, 2018). As also demonstrated by Soltani et al. (2019) this is because the mechanical response of contaminated soils not only depends on the local environment but is also strongly influenced by factors such as the content and type of contaminant, its spatial and temporal variability, soil particle size, bonding characteristics among particles and ion exchange capacity (Fang, 1997).

Soltani et al. (2019) also report a noteworthy summary of earlier studies introducing theoretical concepts governing contamination phenomena with respect to permeability, compressibility and shear strength. Similarly, the article by Mohajeri et al. (2019) is addressing the sensitivity of the mechanical properties, such as soil compressibility and permeability, of bentonite clay treated with chemically modified sawdust contents and laced with various $\mathrm{Pb}\left(\mathrm{NO}_{3}\right)_{2}$ concentrations.

The article by Bakhshipour et al. (2019) aims to determine the effects of acid rain on the compressibility behaviour of two common types of residual soil, including sedimentary residual soil and igneous residual soil. The multi-scale laboratory study also shows the strong effect of long term artificial acidic rain on the soil structure and behaviour.

Soltani et al. (2019), Bakhshipour et al. (2019) and Mohajeri et al. (2019) all contribute to the understanding of the chemomechanical phenomena occurring within edge-of-chaos soil systems to interestingly derive predictable simple patterns of long term behaviour. They can be included into the relevant scientific literature contributions (Federico et al., 2015, 2016; Lambe, 1953; Maio, 1996; Mitchell and Soga, 2005; Santamarina et al., 2002; Todaro et al., 2019) about the pore-fluid-chemistry-dependent soil response as salient and distinguishing characteristic of fine soils. It has to be mentioned that this growing awareness has recently brought Jang and Santamarina (2016) to propose a revised soil classification system. 


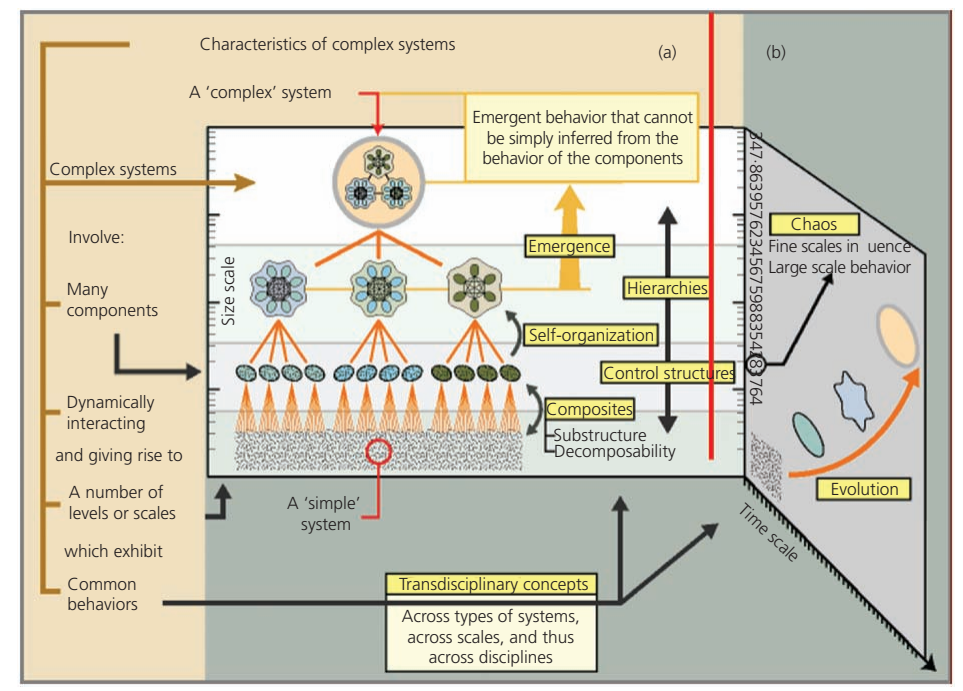

Figure 1. Overview of the characteristics of (a) complex and (b) chaotic systems (after Ferreira, 2001, modified)

The articles by Rodrigues et al. (2019), Alazigha et al. (2019) and Helle and Aagaard (2019) in this issue are instead dealing with remedial strategies to environmental concerns, that is managing and investing for facing such complexity according to sustainable-based approaches. All of them are inspired by a widespread consensus on the need to reduce greenhouse gas emissions to combat climate change and to meet the Kyoto Protocol.

Specifically, the article by Rodrigues et al. (2019) address the use of Alkali-Activated Cement (AAC) as an inorganic material with a chemical structure of polymeric $\mathrm{Si}-\mathrm{O}-\mathrm{Al}$ bonds, that can promote the stabilisation and immobilisation of a wide variety of waste sources containing. The purpose of this experimental study is to evaluate the effect of different curing conditions on the resistance and permeability of an AAC and on the quality of the seepage water. The authors highlight the effect of different conditions of temperature and humidity on the strength results of similar specimens (i.e. the same compositions and curing time).

Alazigha et al. (2019) present an experimental study that explores the effectiveness of Lignosulfonate (LS), a waste by-product known from the paper manufacturing industry, in stabilizing expansive soil. The effectiveness of LS in altering the shrink/swell potential, freeze-thaw/ wet-dry durability, unconfined comprehensive strength, compaction characteristics, permeability, consolidation and soil $\mathrm{pH}$ is explored. The results interestingly show significant and consistent changes in the engineering properties of the tested specimens with $2 \%$ LS addition.

The results of the site investigation carried out by Helle and Aagaard (2019) show the effectiveness of the installation of saltwells filled with potassium chloride in a Norwegian quick clay. The authors investigate the improvement of geotechnical properties and the required time to stabilise the clay volume sufficiently to inhibit retrogressive landslide development. PHREEQC version 3
(Parkhurst and Appelo, 2013) is used to estimate the velocity of the observed in-situ salt migration, aiding prediction of the required time to improve the quick clay volume so that retrogressive landslide development is inhibited.

All the six articles in this issue are facing complex or edge-of-chaos systems of geomaterials trying to solve their complexity both in the knowledge of their behaviour and in predicting the efficacy of remedial strategies. They are all testifying step-forwards of environmental geotechnics, as very much alive discipline that increasingly implements in engineering terms the holistic knowledge of multiscale factors and processes of physical, chemical and mechanical origin.

\section{REFERENCES}

Alazigha DP, Vinod JS, Indraratna B and Heitor A (2019) Potential use of lignosulfonate for expansive soil stabilisation. Environmental Geotechnics 6(7): 480-488, https://doi.org/10.1680/jenge.17.00051.

Bakhshipour Z, Asadi A, Sridharan A and Huat BBK (2019) Acid rain intrusion effects on the compressibility behaviour of residual soils. Environmental Geotechnics 6(7): 460-470, https://doi.org/10.1680/ jenge. 15.00081 .

Baranger M (2002) Chaos, complexity, and entropy. A physics talk for non-physicists. Source: necsi.org/projects/baranger/cce.pdf.

Basu D, Misra A and Puppala A (2015) Sustainability and geotechnical engineering: perspectives and review. Canadian Geotechnical Jorunal 52(1): 96-113.

Cilliers P (1998) Complexity and Postmodernism: Understanding Complex Systems. Routledge, London, UK.

Di Maio C (1996) Exposure of bentonite to salt solution: osmotic and mechanical effects. Geotechnique 46(4): 695-707.

Fang H (1997) Nature of soil and environment. In Introduction to Environmental Geotechnology, 1st ed. CRC Press, Boca Raton, FL, USA, pp. 49-78.

Federico A, Vitone C and Murianni A (2015) On the mechanical behaviour of dredged submarine clayey sediments stabilized with lime or cement. Canadian Geotechnical Journal 52(12): 2030-2040. 
Federico A, Vitone C, Murianni A and Internò G (2016) Plasticity of lime-cement stabilised dredged clayey sediments. Environmental Geotechnics 3(1): 17-27, https://doi.org/10.1680/envgeo.13.00076.

Helle TE and Aagaard P (2019) Predicting required time for stabilising Norwegian quick clays by potassium chloride. Environmental Geotechnics 6(7): 489-502, https://doi.org/10.1680/ jenge. 17.00032

Jang J and Santamarina JC (2016) Fines classification based on sensitivity to pore-fluid chemistry. Journal of Geotechnical and Geoenvironmental Engineering 142(4): 1-8.

Lambe TW (1953) The structure of inorganic soil. Proceedings of the American Society of Civil Engineers 79(10): 1-49.

Levy D (1994) Chaos theory and strategy: theory, application, and managerial implications. Strategic Management Journal 15:167-178.

Lorenz EN (1972) Predictability: does the flap of a butterfly's wings in Brazil set off a tornado in Texas? Proc 139th Annual Meeting of the American Association for the Advancement of Science in Essence of Chaos (1995) Appendix 1, 181.

Mitchell JK and Soga K (2005) Fundamentals of Soil Behaviour. Wiley, Hoboken NJ, USA.

Mohajeri P, bin Selamat MR, Aziz HA, Vakili AH and Farraji H (2019) Geoenvironmental behaviour of lead-contaminated clay with sawdust. Environmental Engineering 6(7): 450-459, https://doi.org/10.1680/ jenge.16.00030.

Parkhurst DL and Appelo CAJ (2013) Description of Input and Examples for PHREEOC Version 3-A Computer Program for Speciation, Batch-Reaction, One-Dimensional Transport, and Inverse Geochemical Calculations. U.S. Geological Survey, Denver, CO, USA, pp. 1-49.

Rodrigues PMSM, Rodrigues C, Cruz N, Rios S and Viana da Fonseca A (2019) Seepage water quality of a soil treated with alkali-activated cement at room temperature. Environmental Geotechnics 6(7): 471479, https://doi.org/10.1680/jenge.17.00039.

Santamarina JC, Klein KA, Palomino A and Guimaraes MS (2002) MicroScale Aspects of Chemical-Mechanical Coupling: Interparticle Forces and Fabric. Balkema, Rotterdam, The Netherlands, pp. 47-64.

Shackelford CD (2005) Environmental issues in geotechnical engineering. In Proceedings of the 16th International Conference on Soil Mechanics and Geotechnical Engineering, vol. 1, pp. 95-122.

Sollecito F, Cotecchia F and Vitone C (2019) Geotechnical characterisation of submarine sediments from a polluted site. In Environmental Science and Engineering 8th International Congress on Environmental Geotechnics (ICEG 2018), pp. 756-763.

Soltani A, Estabragh AR, Taheri A, Deng A and Meegoda JN (2019) Experiments and dimensional analysis of contaminated clay soils. Environmental Geotechnics 6(7): 434-449, https://doi.org/10.1680/ jenge. 18.00018 .

Todaro F, Vitone C and Notarnicola M (2019) Stabilization and recycling of contaminated marine sediments. E3S Web of Conferences (IS-Glasgow 2019) 92: 11004.

UNDRR (United Nations Office for Disaster Risk Reduction) (2019) Global Assessment Report on Disaster Risk Reduction. UNDRR, Geneva, Switzerland.

Vitone C, Federico A, Puzrin A et al. (2016) On the geotechnical characterisation of the polluted submarine sediments from Taranto. Environmental Science and Pollution Research Journal 23(13):12535-12553.

Vitone C, Cotecchia F, Federico A and Viggiani G (2018) On the geomechanical characterisation of complexities in clays: experimental studies. Italian Geotechnical Journal 52(2): 7-29.

Waldrop MM (1992) Complexity: the Emerging Science at the Edge of Order and Chaos. Touchstone, New York, USA 